\title{
Socio Economic Context and Disaster Resilience Among the Farmers Involved in Livestock Rearing in Flood Affected Zones of Kashmir Valley
}

\author{
Sanober Rasool ${ }^{*}$, SA Hamdani ${ }^{1}$, A Fayaz ${ }^{2}$, B Zaffer ${ }^{2}$, B Nabi ${ }^{3}$, S Akhtar ${ }^{4}$, \\ S Taifa ${ }^{5}$, A Hai ${ }^{1}$ and AH Akand ${ }^{1}$ \\ ${ }^{1}$ Division of Veterinary and Animal Husbandry Extension (SKUAST K), Jammu and \\ Kashmir, India \\ ${ }^{2}$ Division of Livestock Production and Management (SKUAST K), Jammu and Kashmir, \\ India \\ ${ }^{3}$ Division of Veterinary Medicine (SKUAST J), Jammu and Kashmir, India \\ ${ }^{4}$ Division of Animal Genetics and Breeding (SKUAST K), Jammu and Kashmir, India \\ ${ }^{5}$ Division of Veterinary Clinical Medicine, Ethics and Jurisprudence (SKUAST K), \\ Jammu and Kashmir, India
}

*Corresponding Author: Sanober Rasool, Division of Veterinary and Animal

Husbandry Extension (SKUAST K), Jammu and Kashmir, India.

\begin{abstract}
The present study was purposively carried out in Kashmir Division of Jammu and Kashmir state that was severely hit by devastating floods in September 2014. The main aim of the study was to elaborate the socio-economic profile and disaster resilience among the farmers involved in livestock rearing when floods hit the Kashmir valley in September 2014. The major findings of the study were that majority of the livestock farmers belonged to middle age group of 41 - 60 years with the average age of 50.48 and were mostly illiterate $(55.42 \%)$ with herd size of $2-3$ cattle/buffalo $(65.42 \%)$ average herd size being 2.00 . On the other hand, majority of the respondents (49.58) were having herd size of 1 - 10 with respect to small ruminants (sheep/goat) with the average being 2.32. A sizeable portion of respondents (48.75\%) were having backyard poultry in the range of 1 - 21 poultry birds per household with the highest mean of 9 poultry birds per household reported from Bandipora District. Major findings indicated that most of the respondents (96.25\%) had no formal social participation except for presence of religion-based participation. With respect to the communication pattern adopted by livestock farmers, majority of them had a low level of extension contact with the informal sources like family members, friends etc. and a medium level of extension contact with the formal sources like Veterinarians, LSA etc. They also had a least exposure to mass media sources related to livestock rearing practices. The findings also showed that the application of indigenous knowledge in the face of hazards and other threats was almost getting diminished as majority of respondents of the study didn't rely on the traditional warning practices/indicators for predicting disaster like floods. Careful selection of building materials was one of the preventive measures taken in advance to reduce the impact of flood by the livestock owners. Education and income were found positively and significantly $(\mathrm{p}<0.05)$ related with level of preparedness of respondents. With respect to economic losses only income was positively and highly significantly $(\mathrm{p}<0.01)$ correlated. Cattle/Buffalo herd size was positive and highly significant $(\mathrm{p}<0.01)$ and that of Sheep/Goat herd size was also positive and significant $(\mathrm{p}<0.05)$ in relation with level of preparedness of respondents to meet disasters. Further flock size of Sheep/Goat was negatively but significantly correlated ( $p<0.05$ ) with economic losses suffered by respondents during floods of 2014. Moreover, mass media exposure was also positively and highly significantly correlated ( $p<0.01$ ) in relation with the level of preparedness of respondents to meet disasters like floods and that with respect to economic losses suffered by livestock farmer during floods of 2014 it was negatively but significantly correlated ( $<<0.05$ ). As far as awareness about zoonotic disease transmitted and livestock rearing safety practices of respondents was concerned, it was found that they were positively and highly significant $(\mathrm{p}<0.01)$ in relation with level of preparedness of respondents to meet any natural calamity.
\end{abstract}

Keywords: Disaster; Extension Contact; Indigenous; Livestock; Mitigation; Preparedness; Social Participation 


\section{Introduction}

India is one of the world's most disaster-prone countries, owing to its extreme geo-climatic circumstances as well as a high level of social vulnerability. According to the National Disaster Management Authority, earthquakes of moderate to very high intensity affect roughly $58.6 \%$ of the country's land area and floods and river erosion affect over 40 million hectares (12\%). Droughts impact 68 percent of its cultivable area while landslides affect about $2 \%$ of its land area. Nearly $5700 \mathrm{~km}$ of its $7516 \mathrm{~km}$ coastline is prone to cyclones and is vulnerable to catastrophes such as tsunamis and storm surges [4]. Every year, at least one large tropical storm hits India, bringing with it a massive tidal wave that kills hundreds of thousands of people [1]. There has been an increase in the number and severity of disasters, posing a hazard not just to people but also to animals. The livestock population is the first to be impacted in any perilous situation induced by a natural calamity, and it is the second most affected subsector after crops, accounting for USD 11 billion or $36 \%$ of all recorded damages and losses [2]. Events like floods have a disastrous effect on a region's economy and people's lives and affect a community in a variety of ways, including human life loss, property damage, agricultural devastation, animal loss, and infrastructure failure. The costs of this natural calamity could go into the billions of dollars, reducing productivity in the impacted areas. Moreover, any states preparedness, response, and recovery mechanisms are almost insufficient which further worsen the situation and cause massive economic losses in terms of livestock losses, infrastructure damage, and available resources to farmers, all of which directly or indirectly impact their livelihood [5]. The socioeconomic profile of livestock owners is very important which gives a clear indication of how well they adopt the livestock disaster management practices. As per Rasool [6] the livestock owners had moderate degree of adoption when it came to the implementation of the livestock rearing safety standards and various environmental hygiene practices followed by them in any disaster were also found to be inadequate pointing to the fact that there is low number of awareness initiatives with respect to disaster mitigation and preparedness by the concerned quarter. Since livestock plays an important role in local and national economies and poor farmers mostly rely on livestock for their livelihood, the government and NGOs should pay more attention to preparedness, response, and recovery mechanisms and more emphasis should be made on uplifting the socioeconomic profile of the farmers so that they can better cope up well with the disaster like events and moreover special types of animal houses should be built in each village [7]. This paper tries to elaborate the socio-economic profile and disaster resilience among the farmers involved in livestock rearing when floods hit the Kashmir valley in September 2014.

\section{Materials and Methods}

The study was purposively carried out in Kashmir Division of Jammu and Kashmir state that was severely hit by a devastating flood in September 2014. Among the various flood affected districts of Kashmir Division, the three districts namely Bandipora, Srinagar and Pulwama were purposively selected based on the highest inundation levels reported in these areas. The Kashmir Division of Jammu and Kashmir State consists of 10 districts. The present study was purposively carried out in three severely flood affected districts viz Pulwama in south, Srinagar in central and Bandipora in north of Kashmir. From each selected district two [2] flood affected blocks were purposively selected based on their livestock population for data collection from affected farmers. Further from each selected block four [4] affected villages were randomly selected for questioning of respondents. Finally, ten (10) affected farmers were randomly selected from each of the selected village making a total of two hundred and forty respondents.

\section{Results and Discussion}

\section{Socioeconomic profile of livestock farmers}

The socio-economic characters of livestock farmers as described in table 1 indicate that majority of the livestock farmers belonged to middle age group of 41 - 60 years with the average age of 50.48. The most probable reason for the results could be that people in their middle age have a better combination of experience with a high enthusiasm to work and are willing to take the responsibility to rear the animals. With respect to Gender, it was found that that majority of the respondents were males (86.67\%) who were actively involved in livestock rearing. It might be due to the fact that women in study area are more confined to their homes and are supposed to look after the indoor house affairs. Moreover, due to society's conservative nature and male dominancy most of the women had a hesitation and were not willing to be interviewed for this research. Pertaining to caste of the respondents as given in table 1 majority of the livestock farmers (65.00\%) belonged to general category, followed by other backward caste category. These results are more or less in line with the proportion of castes present among the population of the state in general and the area of study in particular. A good majority of people $(65.00 \%)$ in were living in nuclear families with higher values for urban areas than their rural counterparts. The possible reason could be that under present modern age people prefer nuclear families over the joint ones for financial stability and better standards of living.

Since education plays an important role in equipping any society to meet any eventualities in a better way. The study revealed that most of the respondents (55.42\%) were illiterate followed by 
those having educational qualification up to middle, high, intermediate, primary, graduate and postgraduate respectively. The findings are a reminder of the literacy levels reflected in any official report in this regard. Overall literacy level of the $\mathrm{J}$ and $\mathrm{K}$ state is 67.16 percent as per 2011 population census. Of that, male literacy stands at 76.75 percent while female literacy is 56.43 percent. It was found that the main occupation of majority of the respondents (32.92\%) was business especially in Srinagar (46.25\%) followed by labour work. As per the research methodology applied to this study, the affected areas selected purposively had a higher proportion of people involved in business activities than the rest of the occupations. Besides the people in selected areas was not enough educated and preferred business as means to earn their livelihood.
The monthly income of majority of respondents (73.33\%) falls under low-income category of ₹ 1000 - 14996 with the overall average for all respondents as 11122.91 giving a clear indication of the fact that the majority of people as involved in business do not get higher returns from it probably due to its smaller scale of operations or some other constraints in way of greater profit. With regard to results of Bandipora it seems that labour as an occupation is a major constraint in higher returns. Moreover, majority of the respondents $(84.58 \%)$ were living in pucca type of houses. The results reflected that people prefer such houses as they can withstand the damage to some extent caused due to any natural calamity and almost (38.30\%) were large farmers with greater than 10 hectares of land.

\begin{tabular}{|c|c|c|c|c|}
\hline \multirow{2}{*}{ Socio-economic variable } & \multicolumn{3}{|c|}{ Districts } & \multirow{2}{*}{ Total } \\
\hline & Srinagar & Bandipora & Pulwama & \\
\hline \multicolumn{5}{|c|}{ Age (Years) } \\
\hline Young $(21-40)$ & $13(16.25)$ & $24(30.00)$ & $25(31.25)$ & $62(25.83)$ \\
\hline Middle $(41-60)$ & $48(60.00)$ & $37(46.25)$ & $40(50.00)$ & $125(52.08)$ \\
\hline Old $(61-80)$ & $19(23.75)$ & $19(23.75)$ & $15(18.75)$ & $53(22.08)$ \\
\hline Mean \pm S. D & $52.73 \pm 12.03$ & $50.08 \pm 13.21$ & $48.63 \pm 14.22$ & $50.48 \pm 13.24$ \\
\hline \multicolumn{5}{|c|}{ Gender } \\
\hline Male & $64(80.00)$ & $71(88.75)$ & $73(91.25)$ & $208(86.67)$ \\
\hline Female & $16(20.00)$ & $9(11.25)$ & $7(8.75)$ & $32(13.33)$ \\
\hline \multicolumn{5}{|c|}{ Caste } \\
\hline General & $62(77.50)$ & $48(60.00)$ & $46(57.50)$ & $156(65.00)$ \\
\hline OBC & $11(13.75)$ & $27(33.75)$ & $30(37.50)$ & $68(28.33)$ \\
\hline SC & $6(7.50)$ & $3(3.75)$ & $3(3.75)$ & $12(5.00)$ \\
\hline ST & $1(1.25)$ & $2(2.50)$ & $1(1.25)$ & $4(1.67)$ \\
\hline \multicolumn{5}{|c|}{ Family type } \\
\hline Nuclear & $58(72.50)$ & $50(62.50)$ & $37(46.25)$ & $145(60.42)$ \\
\hline Joint & $22(27.50)$ & $30(37.50)$ & $43(53.75)$ & $95(39.58)$ \\
\hline \multicolumn{5}{|c|}{ Education status } \\
\hline Illiterate & $40(50.00)$ & $42(52.50)$ & $51(63.75)$ & $133(55.42)$ \\
\hline Primary & $4(5.00)$ & $4(5.00)$ & $3(3.75)$ & $11(4.58)$ \\
\hline Middle & $14(17.50)$ & $14(17.50)$ & $12(15.00)$ & $40(16.67)$ \\
\hline High & $15(18.75)$ & $14(17.50)$ & $8(10.00)$ & $37(15.42)$ \\
\hline Intermediate & $6(7.50)$ & $3(3.75)$ & $3(3.75)$ & $12(5.00)$ \\
\hline Graduate & $1(1.25)$ & $3(3.75)$ & $1(1.25)$ & $5(2.08)$ \\
\hline Post-graduate & $0(0.00)$ & $0(0.00)$ & $2(2.50)$ & $2(0.83)$ \\
\hline \multicolumn{5}{|c|}{ Occupation } \\
\hline Agricultural farming & $5(6.25)$ & $10(12.50)$ & $12(15.00)$ & $27(11.25)$ \\
\hline Livestock Rearing & $14(17.50)$ & $20(25.00)$ & $11(13.75)$ & $45(18.75)$ \\
\hline Business & $37(46.25)$ & $18(22.50)$ & $24(30.00)$ & $79(32.92)$ \\
\hline Labour & $18(22.50)$ & $29(36.25)$ & $26(32.50)$ & $73(30.42)$ \\
\hline Government Service & $6(7.50)$ & $3(3.75)$ & $7(8.75)$ & $16(6.67)$ \\
\hline
\end{tabular}

Citation: Sanober Rasool., et al. "Socio Economic Context and Disaster Resilience Among the Farmers Involved in Livestock Rearing in Flood Affected Zones of Kashmir Valley". Acta Scientific Veterinary Sciences 4.2 (2022): 124-131. 


\begin{tabular}{|l|c|c|c|c|}
\hline \multicolumn{5}{|c|}{ Income } \\
\hline Low (Rs. 1000 - 14996) & $52(65.00)$ & $62(77.50)$ & $62(77.50)$ & $176(73.33)$ \\
\hline Medium (Rs.14997 - 28993) & $23(28.75)$ & $18(22.50)$ & $15(18.75)$ & $56(23.33)$ \\
\hline High (Rs.28994 - 42990) & $5(6.25)$ & $0(0.00)$ & $3(3.75)$ & $8(3.33)$ \\
\hline Mean & 12406.25 & 10118.75 & 10843.75 & 11122.91 \\
\hline \multicolumn{5}{|c|}{ House type } \\
\hline Kutcha & $0(0.00)$ & $2(2.50)$ & $0(0.00)$ & $2(0.83)$ \\
\hline Pacca & $80(0.00)$ & $58(72.50)$ & $65(81.25)$ & $203(84.58)$ \\
\hline Mixed & $0(0.00)$ & $20(25.00)$ & $15(18.75)$ & $35(14.58)$ \\
\hline \multicolumn{5}{|c|}{ Land holding } \\
\hline Landless (0 ha) & $7(8.80)$ & $0(0.00)$ & $0(0.00)$ & $7(2.90)$ \\
\hline Small (1 - 2 ha) & $28(35.00)$ & $0(0.00)$ & $1(1.30)$ & $29(12.10)$ \\
\hline Semi medium (2 - 4 ha) & $41(51.30)$ & $8(10.00)$ & $9(11.30)$ & $58(24.20)$ \\
\hline Medium (4 - 10 ha) & $4(5.00)$ & $22(27.50)$ & $28(35.00)$ & $54(22.50)$ \\
\hline Large (> 10 ha) & $0(0.00)$ & $50(62.50)$ & $42(52.50)$ & $92(38.30)$ \\
\hline
\end{tabular}

Table 1: Distribution of respondents as per their socio-economic characteristics $\mathrm{N}=240$.

(Figures in parenthesis indicate percentage).

\section{Herd Size}

It was found that majority of the respondents (65.42\%) were having herd size of 2 - 3 cattle/buffalo and among the large animals the average herd size was 2.00 . On the other hand, majority of the respondents (49.58) were having herd size of 1 - 10 with respect to small ruminants (sheep/goat) with the average being 2.32. A sizeable portion of respondents (48.75\%) were having backyard poultry in the range of 1 - 21 poultry birds per household with the highest mean of 9 poultry birds per household reported from Bandipora District (Table 2). Since the main occupation of majority of the respondents was business, rearing of livestock was their subsidiary occupation and was mostly kept for daily needs.

\begin{tabular}{|c|c|c|c|c|}
\hline \multirow{2}{*}{$\begin{array}{l}\text { Herd size (no.) } \\
\text { Cattle/Buffalo }\end{array}$} & \multicolumn{3}{|c|}{ Districts } & \multirow{2}{*}{ Total } \\
\hline & Srinagar & Bandipora & Pulwama & \\
\hline $0-1$ & $30(37.50)$ & $17(21.25)$ & $21(26.25)$ & $68(28.33)$ \\
\hline $2-3$ & $48(60.00)$ & $59(73.75)$ & $50(62.50)$ & $157(65.42)$ \\
\hline$>4$ & $2(2.50)$ & $4(5.00)$ & $9(11.25)$ & $15(6.25)$ \\
\hline Mean \pm S. D & $1.73 \pm 0.92$ & $2.08 \pm 0.84$ & $2.18 \pm 0.98$ & $2.00 \pm 0.93$ \\
\hline \multicolumn{5}{|c|}{ Sheep/Goat } \\
\hline Nil & $44(55.00)$ & $25(31.25)$ & $38(47.50)$ & $107(44.58)$ \\
\hline $1-10$ & $35(43.75)$ & $46(57.50)$ & $38(47.50)$ & 119 (49.58) \\
\hline$>11$ & $1(1.25)$ & $9(11.25)$ & $4(5.00)$ & $14(5.83)$ \\
\hline Mean \pm S. D & $0.85 \pm 1.729$ & $4.30 \pm 6.60$ & $1.82 \pm 3.34$ & $2.32 \pm 4.60$ \\
\hline \multicolumn{5}{|c|}{ Poultry (Backyard) } \\
\hline Nil & $42(52.50)$ & $25(50.00)$ & $41(51.25)$ & $108(45.00)$ \\
\hline $1-21$ & $37(46.25)$ & $44(55.00)$ & $36(45.00)$ & $117(48.75)$ \\
\hline $22-24$ & $1(1.25)$ & $10(12.50)$ & $3(3.75)$ & $14(5.83)$ \\
\hline $43-63$ & $0(0.00)$ & $1(1.25)$ & $0(0.00)$ & $1(0.42)$ \\
\hline Mean \pm S. D & $3.26 \pm 4.60$ & $9.18 \pm 9.80$ & $4.47 \pm 7.30$ & $5.64 \pm 7.93$ \\
\hline
\end{tabular}

Table 2: Distribution of respondents as per their present herd size N=240.

(Figures in parenthesis indicate percentage). 
Social participation of various livestock owners

Social participation is seen as an important condition for overall development of people as they gather knowledge and develop social skills while interacting with other people. Major findings indicated that most of the respondents (96.25\%) had no formal social participation except for presence of religion-based participation. The least presence of formal social institutions in the area of study along with routine social barriers especially seen under any conflict-ridden zone add to peoples least participation in them (Table 3).

\begin{tabular}{|c|c|c|c|c|}
\hline \multirow{2}{*}{$\begin{array}{l}\text { Social participation } \\
\text { (Religious organizations) }\end{array}$} & \multicolumn{3}{|c|}{ Districts } & \multirow{2}{*}{ Total } \\
\hline & Srinagar & Bandipora & Pulwama & \\
\hline Working committee member & $0(0.00)$ & $1(1.25)$ & $0(0.00)$ & $1(0.42)$ \\
\hline General body member & $5(6.25)$ & $2(2.50)$ & $1(1.25)$ & $8(3.33)$ \\
\hline No formal participation & $75(93.75)$ & $77(96.25)$ & $79(98.75)$ & $231(96.25)$ \\
\hline
\end{tabular}

Table 3: Distribution of respondents as per their social participation N=240.

Communication pattern adopted by livestock farmers

Communication channels play a very important role in the process of development. Such channels are necessary for bringing a change in knowledge, awareness, behaviour and attitude of the people. The communication pattern of the livestock farmers related to livestock rearing was studied under different variables like informal and formal extension contacts and mass media exposure.

Informal and Formal extension contact and mass media exposure of the respondents

Communication plays a very important role in rural development. The communication networks set up in the rural areas facilitate access by the local people to the service and the information for use in diverse fields of life.

In the study the informal extension contact of majority of respondents $(72.08 \%)$ was found to be of low level whereas the formal extension contact of majority of farmers $(52.50 \%)$ was of medium level (Table 4). The results are pointer to the fact that extension contact with both the sources i.e., formal and informal need to be strengthened with special emphasis on formal extension contact for better knowledge, feedback, control and for better preparedness for any disaster. The probable reason could be ill prepared extension delivery system and lesser social participation to have an impact on extension contact. Similar results were found by [3].

The overall mass media exposure of the respondents depicts that majority of the respondents (62.24\%) were having least exposure to mass media sources delivering messages related to livestock rearing practices. The probable reason for lower mass media exposure could be explained by the fact that a large majority of respondents were illiterate and as such could not make much use of these mass media sources. Further the factors such as low family income might add to lesser mass media exposure among farmers. Interestingly, none of the respondents have a high level of mass media exposure in Bandipora district. This could probably be explained by the fact that the region is far flung affecting the accessibility of mass media sources in addition to other routine cause of implement.

\begin{tabular}{|l|c|c|c|c|}
\hline \multirow{2}{*}{$\begin{array}{l}\text { Communication vari- } \\
\text { able }\end{array}$} & Srinagar & Bandipora & \multirow{2}{*}{ Pulwama } & \\
\cline { 2 - 4 } Extension contacts & \\
\hline \multicolumn{3}{|c|}{ Informal extension contact (score) } & \\
\hline Low (4-6) & $66(82.50)$ & $52(65.00)$ & $55(68.75)$ & $173(72.08)$ \\
\hline Medium (7-9) & $12(15.00)$ & $25(31.25)$ & $24(30.00)$ & $61(25.42)$ \\
\hline High (10-12) & $2(2.50)$ & $3(3.75)$ & $1(1.25)$ & $6(2.50)$ \\
\hline \multicolumn{5}{|l|}{ Formal extension contact (score) } \\
\hline Low (6-7) & $29(36.25)$ & $34(42.50)$ & $21(26.25)$ & $84(35.00)$ \\
\hline Medium (8-9) & $43(53.75)$ & $38(47.50)$ & $45(56.25)$ & $126(52.50)$ \\
\hline High (10-11) & $8(10.00)$ & $8(10.00)$ & $14(17.50)$ & $30(12.50)$ \\
\hline
\end{tabular}




\begin{tabular}{|l|c|c|c|c|}
\hline $\begin{array}{l}\text { Overall Mean } \pm \\
\text { S.D(Informal + Formal) }\end{array}$ & $13.44 \pm 2.62$ & $13.92 \pm 2.73$ & $14.31 \pm 2.67$ & $13.89 \pm 2.67$ \\
\hline \multicolumn{5}{|l|}{ Mass media exposure (score) } \\
\hline Low (5-7) & $61(69.09)$ & $52(56.58)$ & $56(61.09)$ & $169(62.24)$ \\
\hline Medium (8-10) & $16(24.55)$ & $28(43.42)$ & $23(36.91)$ & $67(34.98)$ \\
\hline High (11-13) & $3(6.36)$ & $0(0.00)$ & $1(2.00)$ & $4(2.78)$ \\
\hline Mean \pm S. D & $6.87 \pm 1.47$ & $6.93 \pm 1.42$ & $6.87 \pm 1.58$ & $6.89 \pm 1.49$ \\
\hline
\end{tabular}

Table 4: Distribution of respondents as per their extension contact and mass media exposure N=240.

(Figures in parenthesis indicate percentage)

Indigenous livestock disaster management practices

Indigenous knowledge is also called traditional knowledge or local knowledge or farmer's wisdom and is mostly defined as the knowledge that gets accumulated over generations of living in a particular environment. The application of indigenous knowledge in the face of hazards and other threats is generally referred to as adaptive mechanism or traditional coping mechanism. This section tries to explore the traditional knowledge associated with disaster like floods.

Traditional warning indicators to predict the occurrence of flood

Results depicted that majority of the respondents (30.41\%) don't rely on traditional warning indicators to predict the occurrence of flood pointing to the fact that new generation livestock farmers have least faith on ITK's due to which their reliance on traditional knowledge has decreased. However, use of traditional water level markers to predict the occurrence of flood was reported by few respondents $(20.00 \%)$ followed by change in specific local weather conditions. Interestingly, some of the unconventional indicators were also followed among some of the respondents like chirping of birds/change in animal behaviour increase noise level in river and level of debris and croaking of frogs. The most important adjacent river to the study area is River Jhelum. The level of this river keeps on changing with the influx of water and is closely being monitored by people living in and around it as a means of awareness about the chances of flood. Officially some of the spots have been designated to check and report the levels and are major indicators of any flood situation in the valley. This probably has led to a greater faith of individuals on the levels as a major indicator of floods. The specific local weather conditions in any place are always of a great help in giving an idea about the prevailing situation so in the case here. Findings of (1) indicated that traditional weather forecasting of a typhoon and flood is imminent when insects start incessant chirping, spider spin shorter and thicker webs and deer becomes restless.

\begin{tabular}{|l|c|c|c|c|}
\hline \multirow{2}{*}{ Traditional early warning indicators } & \multicolumn{3}{|c|}{ Districts } & \multirow{2}{*}{ Total } \\
\cline { 2 - 5 } & Srinagar & Bandipora & Pulwama & \\
\hline Change in specific local weather conditions & $15(18.75)$ & $22(27.50)$ & $9(11.25)$ & $46(19.16)$ \\
\hline Chirping birds/change in animal behavior & $19(23.75)$ & $7(8.75)$ & $11(13.75)$ & $37(15.41)$ \\
\hline Use of traditional water level markers & $10(12.50)$ & $20(25.00)$ & $18(22.50)$ & $48(20.00)$ \\
\hline Typical noise level in rivers and level of debris & $6(7.50)$ & $12(15.00)$ & $3(3.75)$ & $21(8.75)$ \\
\hline Croaking of frogs & $2(2.50)$ & $3(3.75)$ & $10(12.50)$ & $15(6.25)$ \\
\hline Don't rely on traditional indicators & $23(35.00)$ & $16(20.00)$ & $29(36.25)$ & $73(30.41)$ \\
\hline
\end{tabular}

Table 5: Distribution of respondents according to use of traditional warning indicators to predict the occurrence of flood $\mathrm{N}=240$.

(Figures in parenthesis indicate percentage).

Indigenous preventive disaster management practices

Careful selection of building materials was the main preventive measure taken in advance by majority of respondents, followed by contingency plan to move animals in disaster. The results can be explained on the fact that the materials used have more visible and tangible impact than the other preventive measures leading to its greater adoption (Table 6). 


\begin{tabular}{|c|c|c|c|c|c|}
\hline \multirow{2}{*}{ Preventive measures adopted } & \multicolumn{3}{|c|}{ Level of adoption } & \multirow{2}{*}{$\begin{array}{c}\text { Average } \\
\text { score }\end{array}$} & \multirow{2}{*}{ Rank } \\
\hline & Always & Sometimes & Never & & \\
\hline Careful selection of construction site & $23(9.58)$ & $39(16.25)$ & $178(74.17)$ & 1.35 & VII \\
\hline Careful selection of building materials & $69(28.75)$ & $117(48.75)$ & $54(22.50)$ & 2.06 & I \\
\hline Regular control over physical condition of shed & $27(11.25)$ & $75(31.25)$ & $138(57.50)$ & 1.53 & IV \\
\hline Stock of adequate feed/fodder & $58(24.17)$ & $74(30.83)$ & $108(45.00)$ & 1.79 & III \\
\hline Emergency medicine in stock & $13(5.42)$ & $42(17.50)$ & $185(77.08)$ & 1.28 & VIII \\
\hline Insurance cover to livestock & $33(13.75)$ & $57(23.75)$ & $150(62.50)$ & 1.51 & $\mathrm{~V}$ \\
\hline Contingency plan to move animals in disaster & $54(22.50)$ & $91(37.92)$ & $95(39.58)$ & 1.82 & II \\
\hline Specific arrangement for grazing animals & $4(1.67)$ & $32(13.33)$ & $204(85.00)$ & 1.16 & IX \\
\hline Regular check on weather forecast & $14(5.83)$ & $66(27.50)$ & $160(66.67)$ & 1.39 & VI \\
\hline
\end{tabular}

Table 6: Distribution of respondents according to preventive measures taken to reduce the impact of disasters like floods N=240.

(Figures in parenthesis indicate percentage).

Preparation and economic losses suffered during floods of 2014

It was found that that (Table7) education and income is positively and significantly $(\mathrm{p}<0.05)$ related with level of preparedness of respondents in order to reduce the impact of disaster like floods. Since education enlarges one's horizon, increases Knowledge, skills and creates awareness among the respondents regarding the pros and cons of any disaster like floods thereby making them well prepared in advance to cope up with any calamity as compared to those who have low knowledge about the same. The positive and significant relationship of preparedness level with income is justified by the fact that those with better income may have adequate resources/inputs which could enhance better preparedness efforts of the respondents in case of any natural disaster. With respect to economic losses only income is positively and highly significantly $(p<0.01)$ correlated. It can be attributed to the fact that more income also means more investment which in turn means greater risk of loss during any disaster.

Findings also depicted that Cattle/Buffalo herd size is positive and highly significant $(\mathrm{p}<0.01)$ and that of Sheep/Goat herd size is positive and significant $(\mathrm{p}<0.05)$ in relation with level of preparedness of respondents to meet disasters. The probable reason could be more the livestock an animal herder has, more is his level for disaster preparedness and immediate response to the situation.
This can be attributed to economics involved behind that is more livestock means more investment involved which in turn means greater risk of loss during disaster. Further flock size of Sheep/ Goat is negatively but significantly correlated ( $p<0.05$ ) with economic losses suffered by respondents during floods of 2014.

Moreover, mass media exposure is positively and highly significantly correlated $(\mathrm{p}<0.01)$ in relation with the level of preparedness of respondents to meet disasters like floods and that with respect to economic losses suffered by livestock farmer during floods of 2014 it is negatively but significantly correlated ( $p<0.05)$. The results are in line with the fact that media plays a crucial role in updating information to target audience and create awareness that allows people to make the necessary decisions and prevent any loss further. However, results also indicate that extension system needs to be reformed so that people who are acquainted with formal as well as informal extension contact have positive and significant result with level of preparedness to meet any natural calamity. With respect to the awareness about zoonotic disease transmitted and livestock rearing safety practices of respondents, they are found positively and highly significant $(\mathrm{p}<0.01)$ in relation with level of preparedness of respondents to meet any natural calamity. The probable reason could be that the people who are aware in these aspects are well equipped to deal with situation like disasters. 


\begin{tabular}{|c|c|c|}
\hline \multirow[b]{2}{*}{ Variables } & \multicolumn{2}{|c|}{ Correlation coefficient } \\
\hline & $\begin{array}{l}\text { Correlation with respect } \\
\text { to level of preparedness }\end{array}$ & $\begin{array}{l}\text { Economic } \\
\text { losses }\end{array}$ \\
\hline Age & 0.036 & 0.069 \\
\hline Education & $0.150^{*}$ & 0.048 \\
\hline Income & $0.162^{*}$ & $0.182^{* *}$ \\
\hline Land holding (ha) & 0.100 & 0.067 \\
\hline \multicolumn{3}{|l|}{ Herd Size } \\
\hline Cattle/Buffalo & $0.196^{* *}$ & -0.116 \\
\hline Sheep/Goat & $0.149^{*}$ & $-0.189 *$ \\
\hline \multicolumn{3}{|c|}{ Communication Behavior } \\
\hline Informal contacts & 0.105 & -0.011 \\
\hline Formal contacts & 0.106 & 0.118 \\
\hline Mass media exposure & $0.180^{* *}$ & $-0.079 *$ \\
\hline \multicolumn{3}{|c|}{$\begin{array}{l}\text { Awareness about Zoonosis and livestock safety rearing } \\
\text { practices }\end{array}$} \\
\hline $\begin{array}{l}\text { Knowledge about } \\
\text { disease transmitted }\end{array}$ & $0.182^{* *}$ & 0.071 \\
\hline $\begin{array}{l}\text { Livestock rearing } \\
\text { safety practices }\end{array}$ & $0.311^{* *}$ & 0.074 \\
\hline
\end{tabular}

Table7: Correlation of various variables of respondents with level of preparation and economic losses suffered during floods of 2014.

$$
\begin{aligned}
& { }^{*} \text { Correlation is significant at }(\mathrm{p}<0.05) \\
& { }^{* *} \text { Correlation is significant at }(\mathrm{p}<0.01)
\end{aligned}
$$

\section{Conclusion}

It was concluded that the socio-economic status of livestock farmers had a profound effect on forces that affected level of preparedness of respondents during the floods of 2014. Since communication channels play a very important role in the process of development. These channels are necessary for bringing a change in knowledge, awareness, behaviour and attitude of the people, so the focus should be on improving the extension contact and mass media exposure of farmers for better awareness about the management of livestock during any natural calamity. The poor and underprivileged groups in India are the ones that suffer the most in terms of human and property damage when tragedy strikes. Not only are they the most hit, but the social, economic, and political conditions in which they live impede their ability to recover from tragedy. Many developing countries' institutional disaster-response procedures are insufficient to tackle the issue. This leads to a significant loss of human and livestock life that could have been averted to some extent if readiness, reaction, and recovery procedures had been in place. People with low socioeconomic status are less prepared for disasters than others, though this may be due to the fact that people with low socioeconomic status cannot always afford more expensive preparedness actions, such as purchasing flood or earthquake insurance or making home improvements to increase disaster resilience in certain types of disasters. It was also found that

most of livestock farmers did not rely on traditional warning practices indicating that new generations don't have any faith on ITKs due to which their reliance on ITK has decreased. So, the need of the hour is to preserve the Indigenous Knowledge related to disaster management and improve the planning, preparedness response, herd evacuation measures and proper channels should be effectively used for better risk communication amongst the livestock owners.

\section{Bibliography}

1. Acharya S. "Presage biology: Lessons from nature in weather forecasting". Indian Journal of Traditional Knowledge 10.1 (2011): 114-124.

2. FAO. "The impact of Natural Hazards and disasters on agriculture and food security and Nutrition security" (2015): 1-54.

3. Kumar P. "Effectiveness of communication pattern for Animal disaster management in Bihar". PhD thesis, Birsa Agricultural University Kanke, Ranchi, Jharkhand (2016).

4. NDMA. "National Disaster Management Authority Government of India" (2011).

5. Rasool S., et al. "A study of economic losses suffered by livestock farmers during the floods of 2014 in Jammu and Kashmir (India)". Journal of Entomology and Zoology Studies 8.2 (2020a): 1091-1094.

6. Rasool S., et al. "Awareness of Kashmiri livestock owners with respect to public health issues, zoonosis and environmental hygiene in flood affected areas of Kashmir division ( $\mathrm{J}$ and $\mathrm{K}$, India)". Journal of Pharmacognosy and Phytochemistry 9.4 (2020b): 671-676.

7. Rasool S., et al. "Effects on Feeds and Housing Management of Livestock during 2014 Floods in Jammu and Kashmir, India". Journal of Krishi Vigyan 8.2 (2020c): 98-103.

\section{Assets from publication with us}

- Prompt Acknowledgement after receiving the article

- Thorough Double blinded peer review

- Rapid Publication

- Issue of Publication Certificate

- High visibility of your Published work

Website: www.actascientific.com/ Submit Article: www.actascientific.com/submission.php Email us: editor@actascientific.com Contact us: +919182824667 